\title{
IDIOPATHIC CHOLESTASIS IN THE NEONATAL PERIOD
}

\author{
BY \\ H. STEIN and C. ISAACSON \\ From the Departments of Paediatrics and Pathology, Baragwanath Hospital, \\ and the South African Institute for Medical Research, Johannesburg
}

(RECEIVED FOR PUBLICATION JULY 24, 1961)

In a recent study (Nakai and Landing, 1961) it has been shown that, apart from bile duct atresia which may be intra- or extra-hepatic, the diseases associated with bile stasis in the first three months of life are hepatitis, erythroblastosis foetalis, galactosaemia and congenital gastro-intestinal anomalies such as duodenal atresia. It has also been shown that premature babies are predisposed to the development of cholestasis. It is suggested by the authors of this study that as well as bile duct obstruction, biochemical dysfunction of liver cells and possibly disturbance of hepatic blood flow may cause bile stasis and are therefore relevant to the development of the inspissated bile syndrome.

We describe four newborn babies presenting with the clinical and histological picture of bile stasis who, apart from prematurity, had none of the other associated abnormalities.

\section{Case Reports}

Case 1. A 15-day-old Bantu female child was admitted with a diagnosis of jaundice and prematurity. There had been no illness during pregnancy, and the delivery was normal. There had been no early neonatal jaundice, and jaundice first developed at 12 days of age. Stools and urine had always been normal in colour.

The admission weight was $5 \mathrm{lb}$. The child was markedly jaundiced; there was no pallor. The liver edge was felt one and a half fingers below the costal margin in the mid-clavicular line, and the tip of the spleen could be felt. Stools observed in the ward varied from clay coloured to yellow.

Laboratory investigations showed that both stercobilin and bilirubin were present in the stools. The urine contained +++ of bile but no urobilin. Blood count revealed haemoglobin $21 \mathrm{~g} . / 100 \mathrm{ml}$., white blood cells 11,500 per c.mm. Prothrombin index was $98 \%$. Wassermann reaction and Coombs' test were negative. Total serum bilirubin level was $18 \cdot 3 \mathrm{mg} . / 100 \mathrm{ml}$. $(14 \cdot 8$ $\mathrm{mg}$. direct and $3.5 \mathrm{mg}$. indirect). The alkaline phosphatase was 26.9 King-Armstrong units. Serum proteins: $6 \cdot 4 \mathrm{~g}$. total (4 g. albumin and $2 \cdot 4 \mathrm{~g}$. globulin). Liver function tests: thymol turbidity 5.5 units, zinc sulphate turbidity 10 units, thymol flocculation negative and zinc sulphate flocculation 3 units. The serum glutamic oxalacetic transaminase level was 285 units, the normal being 34 to 98 . There was no glycosuria or albuminuria, and no cytomegalic inclusion bodies were found in centrifuged urine.

Prednisone and penicillin were administered. The child continued to deteriorate and died on the tenth day after a bout of diarrhoea.

Autopsy. There was marked bile-staining of all the viscera, and this was particularly marked on the intima of blood vessels. The liver $(160 \mathrm{~g}$.) presented a smooth, bile-stained surface. On section the parenchyma was dark green in colour, but there was no evidence of fibrosis. The gall-bladder contained a small quantity of light green bile and this was expressed from the gall-bladder into the duodenum without any difficulty. The kidneys showed numerous small pale abscesses $\frac{1}{2}-1 \mathrm{~mm}$. in diameter scattered throughout the parenchyma. There was also bile-staining of the medullary pyramids and of the pelvis. The brain did not show any kernikterus.

Microscopic Examination. The normal architectural pattern of the liver was preserved without any evidence of necrosis or collapse of the lobular parenchyma, and the liver cells were normal in the main (Fig. 1). The bile channels in the portal tracts were normal. A few portal tracts showed slightly increased fibrosis and moderate infiltration with lymphocytes and occasional neutrophils. The most striking feature was the marked bile stasis. There were bile plugs in the canaliculi, and the centrilobular liver cells contained bile granules in their cytoplasm (Fig. 2). Many Kupffer cells contained bile. The bile ducts in the portal tracts were generally free of pigment although an occasional one contained a small bile plug.

Section of the kidneys showed a severe acute pyelonephritis.

Case 2. A 30-day-old Bantu female was admitted for jaundice and prematurity. There had been no illness during pregnancy and delivery was normal. The child's twin was well and thriving. Early neonatal jaundice had not been noted. The jaundice had developed for the first time on the 28th day. The history of the colour of the stools could not be determined.

Admission weight was $3 \mathrm{lb} .12 \mathrm{oz}$. The child was very jaundiced and moderately pale. The liver was enlarged one finger breadth below the costal margin and the spleen was not felt. From observation in the ward the stools were consistently clay coloured. 


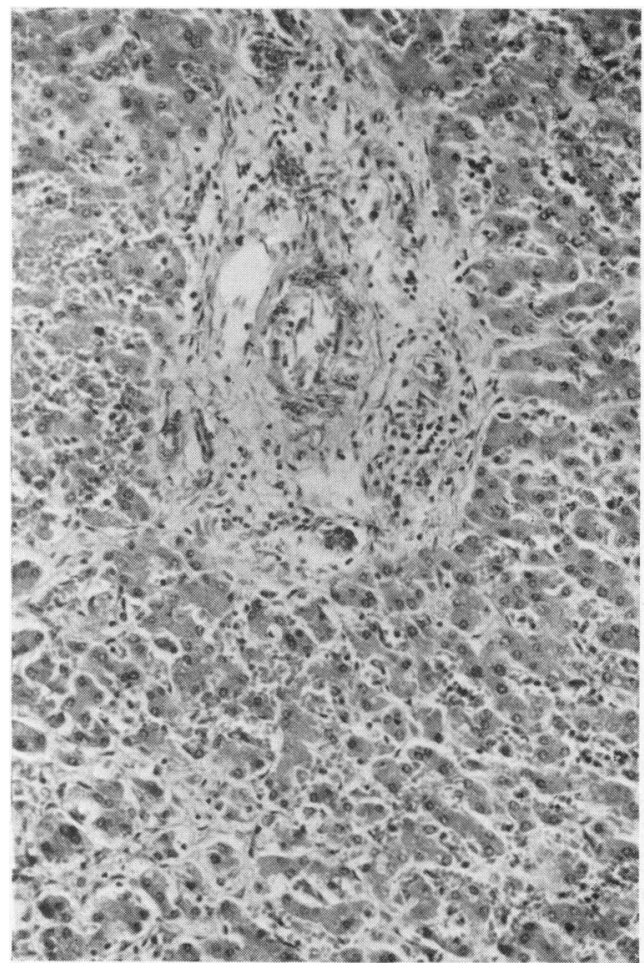

FIG 1.-Section of liver from Case 1. There is preservation of the normal architecture and only minimal cellular infiltrate in the portal tracts. (Haematoxylin and eosin $\times 124$.)

Laboratory investigations showed that the urine contained +++ of bile but no urobilin. The blood count: haemoglobin $11 \mathrm{~g} . / 100 \mathrm{ml}$., white cell count 18,000 per c.mm. Prothrombin index was $70 \%$. Wassermann reaction was negative. The serum bilirubin was $22.5 \mathrm{mg} . / 100 \mathrm{ml}$. (14.8 mg. direct and $7 \cdot 7$ mg. indirect). The alkaline phosphatase was $14 \mathrm{King}$ Armstrong units. The serum protein level was $4.7 \mathrm{~g}$./ $100 \mathrm{ml}$. (albumin $2.4 \mathrm{~g}$. and globulin $2 \cdot 3 \mathrm{~g}$.). Liver function tests: thymol turbidity 3.5 units, zinc sulphate turbidity 3 units, thymol flocculation negative, zinc sulphate flocculation 2 units Blood culture was negative. There was no glycosuria or albuminuria or cytomegalic inclusion bodies in the urine.

Jaundice increased during the stay in hospital. The child was treated for gastro-enteritis which developed in the ward. There was no response and death occurred on the tenth hospital day.

Autopsy. There was marked bile-staining of all organs. The liver was smooth, firm and dark green in colour. The gall-bladder contained a small quantity of green bile. The biliary passages were patent and bile was easily expressed from the gall-bladder into the duodenum. Section of the brain did not reveal any evidence of kernikterus.

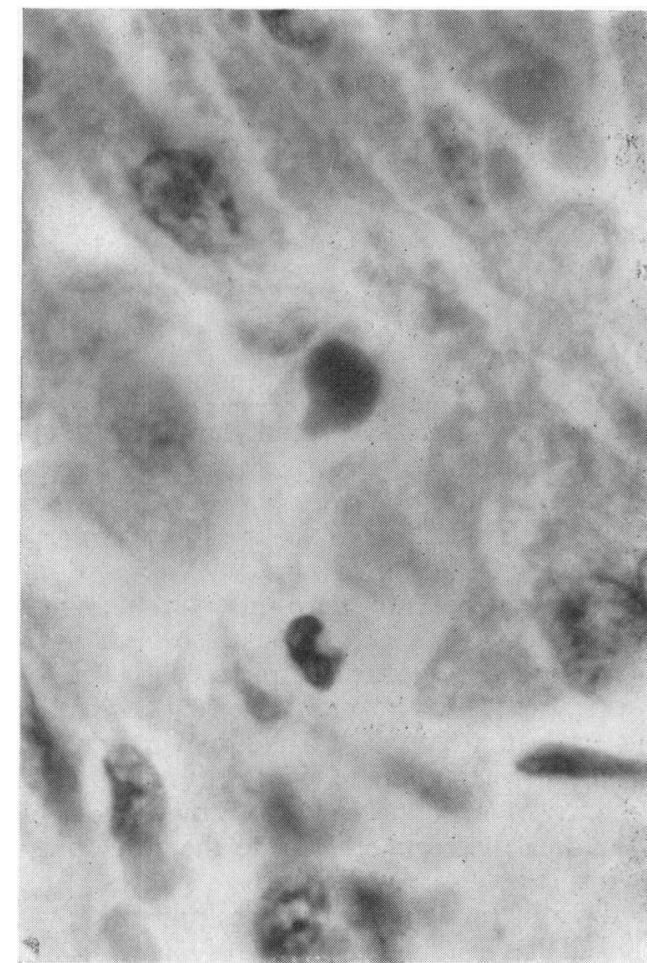

FIG. 2.-Bile plugs in the canaliculi.

(Haematoxylin and eosin $\times 1,222$.)

Microscopic Examination. The architectural pattern of the liver was preserved (Fig. 3). There was considerable bile stasis particularly in the centrilobular regions, where many hepatic cells showed feathery degeneration (Fig. 4). There was no evidence of necrosis or inflammation and giant liver cells were not found. The bile ducts in the portal tracts were normal and there was no increased fibrosis.

Case 3. A Bantu female was admitted for prematurity on the second day of life. The mother had been well during pregnancy, and delivery was normal. On admission the weight was $3 \mathrm{lb} .15 \mathrm{oz}$., and all systems were normal. Progress was good. There was no jaundice; this developed while the child was in the ward on the seventeenth day of life. Stools were quite normal.

Laboratory investigations showed that there were no abnormalities chemically or microscopically in the urine. Blood count: haemoglobin $16.8 \mathrm{~g} . / 100 \mathrm{ml}$. with 7,000 white blood cells per c.mm. Wassermann reaction was negative. Serum bilirubin was $5.7 \mathrm{mg} . / 100 \mathrm{ml}$., of which $3.6 \mathrm{mg}$. were direct and $2.1 \mathrm{mg}$. indirect. The child died of bronchopneumonia on the twenty-first day of life. 


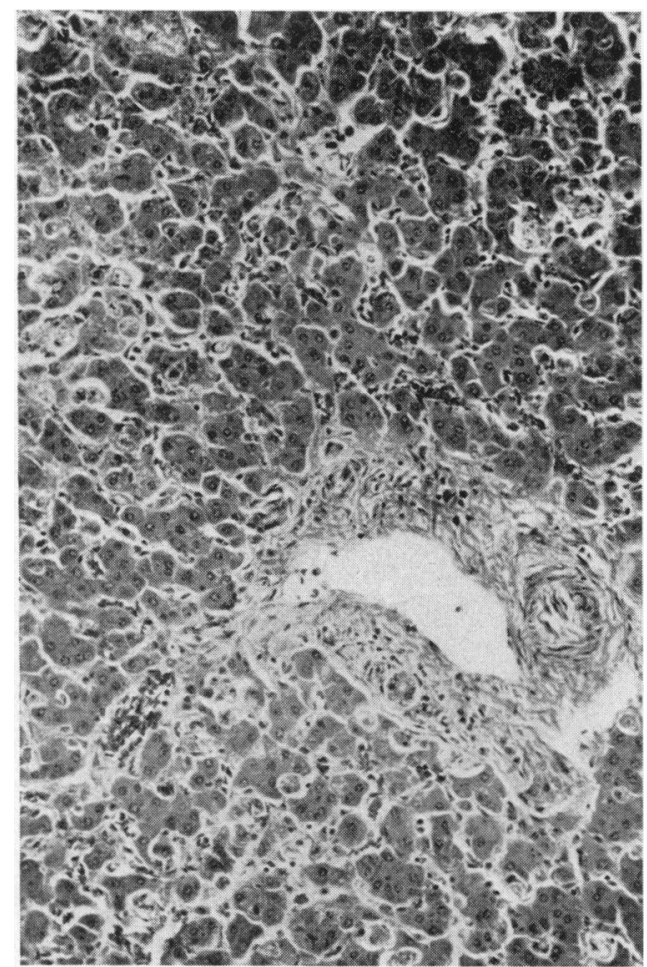

FIG. 3.-The liver cells are essentially normal and the lobular architecture is well preserved. (Haematoxylin and eosin $\times 124$.)

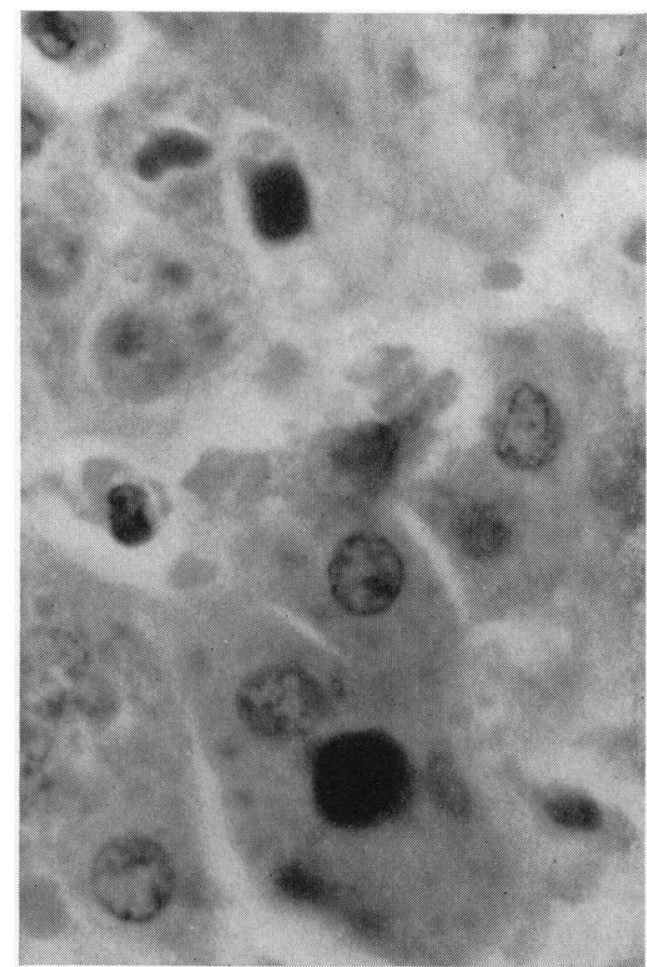

FIG. 4.-High power of Fig. 3, showing the marked bile stasis. (Haematoxylin and eosin $\times 1,222$.)

dark for three days before admission. A day before admission the respiration had become difficult, and the child had refused to take tiie breast.

There had been an episode of diarrhoea at 12 days of age; this lasted for three days and ceased on out-patient therapy.

On admission the infant was critically ill, markedly jaundiced, acidotic and dehydrated. There was congenital absence of three fingers of the right hand. The liver was just palpable. There was no splenomegaly. Death occurred within two hours of admission.

Autopsy. The liver was not enlarged, but was markedly bile-stained. The extrahepatic biliary passages were patent. The gall-bladder was not distended and contained a moderate quantity of dark green bile. There was no kernikterus.

Microscopic Examination. The liver showed a picture essentially similar to the previous cases. The lobular architecture was well preserved and no inflammatory infiltrate was present. There was no increased fibrosis (Fig. 5). Bile stasis was extreme, large plugs filling the canaliculi and many hepatic cells showing severe bile impregnation (Fig. 6). Many of the liver cells in the centrilobular zones showed 'feathery degeneration'. Giant liver cells were not seen. 


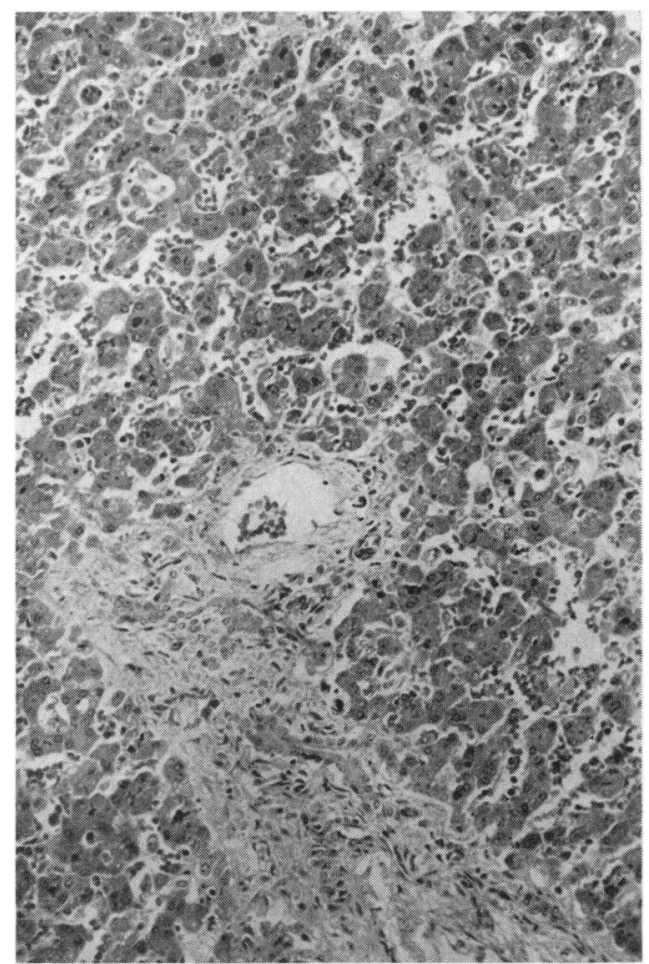

FIG. 5.-Section of the liver, showing normal portal tract with some widening of the liver cell plates. (Haematoxylin and eosin $\times 124$.)

Section of the lungs showed focal intra-alveolar haemorrhage.

\section{Discussion}

The cases described had several features in common. All were premature infants; early neonatal hyperbilirubinaemia had not been noted in any of them; all infants developed jaundice between 12 and 28 days of life; the jaundice was at least partially obstructive in all cases; serum bilirubin was predominantly direct in the three cases where it was ascertained, and there was marked bilirubinuria and absence of urobilinuria in these three cases; none of the patients survived beyond 10 days after onset of jaundice. In the three cases where the Wassermann reaction was done it proved to be negative, and no galactose or cytomegalic inclusion bodies were found in the urine of the three patients who were examined for this.

From the clinical point of view the picture of an intermittent obstructive jaundice presenting between 12 and 28 days suggested a limited number of possibilities. The inspissated bile syndrome following haemolytic disease seemed an unlikely aetiology because of the absence of a history of haemolytic

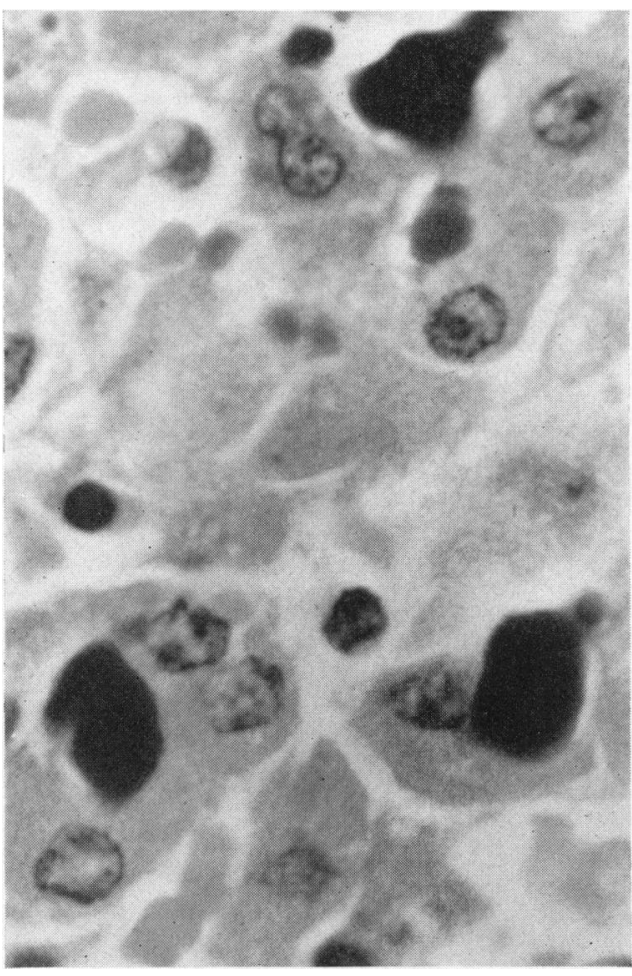

FIG. 6.-High power of Fig. 5, showing intense bile stasis. (Haematoxylin and eosin $\times 1,222$.)

disease or neonatal jaundice in Cases 1,2 and 4, and the absence of objective evidence of haemolysis in Case 3 who was observed in hospital from the second day of life. Congenital atresia of the bile ducts was considered unlikely in view of the picture of incomplete obstruction and the low level of alkaline phosphatase. There was no evidence of galactosaemia or congenital gastro-intestinal anomalies. Neonatal hepatitis appeared the most likely diagnosis in view of the time of onset, the picture of incomplete obstruction, the absence of neonatal haemolysis and the absence of galactose and cytomegalic inclusion bodies in the urine; in fact this was the presumptive ante-mortem diagnosis. However, histological examination failed to confirm this diagnosis. The characteristic pattern of neonatal hepatitis with giant liver cells, necrosis, cellular infiltrate, haemosiderin deposition and disturbance of the architecture was not observed, and the only significant finding in every case was severe intrahepatic cholestasis. In some instances there was slight widening of the liver cell plates, but the lobular architecture was always preserved. The severe bile-stasis had sometimes produced 'feathery' 
degeneration of hepatic cells, but inflammatory cell infiltration was not a feature in any of the cases, and liver cell damage was not marked.

Popper and Schaffner (1959) state that intrahepatic cholestasis may occur as a component of hepatic disease as in hepatitis or cirrhosis, or as the result of administration of drugs such as chlorpromazine, sulphanilamide, thiouracil and others, or as the dominant feature of hepatic disease. Our cases would fall into the last category as there was no histological evidence of significant parenchymal damage nor a history of drug administration. Eppinger (1937) and Watson and Hoffbauer (1946) consider that hepatitis may take one of two forms in adults; the hepatocellular type with mild jaundice and disturbed liver histology, and the cholangiolitic type characterized by prolonged severe obstructive jaundice and bile stasis with little or no parenchymal liver damage over and above that which may have been caused by cholestasis. This type of isolated cholestasis in hepatitis, while occurring occasionally in adults, is extraordinarily rare in the newborn. However, Popper and Schaffner (1957) state that certain cases of neonatal hepatitis may show only cholestasis, and H. Popper (1960, personal communication) suggests that in such instances there may be a specific lesion of the biliary micro-villi resulting in abnormally viscous bile. This is in contrast to almost all descriptions of the histology of this condition with giant liver cells, disruption of hepatic cell plates and architecture, haemosiderin deposition and fibrosis.

There is one report of neonatal jaundice presenting a pathological picture bearing resemblance to our cases; this is described by Craig, Gellis and Hsia (1955) in a review of 98 cases of cirrhosis of the liver in children seen in Boston over 30 years. One of their cases, who presented with obstructive jaundice at 10 days of age, died at 4 months of age; autopsy showed a normal extrahepatic tree, early periportal cirrhosis, but few necrobiotic changes in the parenchymal cells and no giant cells. The bile canaliculi showed gross bile stasis. They felt that this was a picture of cholangitis due to a bile infection.

Whether neonatal hepatitis can occur as a pure cholangiolitis, as it is suggested that infective hepatitis in adults can, remains to be established. In our cases the clinical diagnosis was neonatal hepatitis. However, the liver histology of these cases was so different from that of classical neonatal hepatitis, as seen at this hospital (Isaacson, 1956), that it is exceedingly difficult to accept these as the same entity. It appears that our cases must be looked upon as cholestasis of prematurity secondary to cholangiolitis of undetermined origin.

\section{Summary}

Four cases of neonatal cholestasis of undetermined aetiology are described. The relation to neonatal hepatitis is considered.

The authors wish to thank the Superintendent for permission to publish, Dr. E. Kahn and Dr. S. Wayburne for access to case records, and the Director of the South African Institute for Medical Research for facilities granted. Mr. M. Ulrich of the photographic department of the South African Institute for Medical Research produced the photomicrographs. Thanks are also due to Professors H. Popper, J. M. Craig and B. J. P. Becker for advice.

\section{REFERENCES}

Craig, J. M., Gellis, S. S. and Hsia, D. Y. Y. (1955). Cirrhosis of the liver in infants and children. A.M.A. Amer. J. Dis. Child., 90, 299.

Eppinger, H. (1937). Die Leberkrankheiten: Allgemeine und spezielle Pathologie und Therapie der Leber. Springer, Vienna.

Isaacson, C. (1956). Neonatal hepatitis. S. Afr. med. J., 30, 980.

Nakai, H. and Landing, B. H. (1961). Factors in the genesis of bile stasis in infancy. Pediatrics, 27, 300 .

Popper, H. and Schaffner, F. (1957). Liver: Structure and Function, p. 462. McGraw-Hill, London. - (1959). Pathology of jaundice resulting from intrahepatic cholestasis. J. Amer. med. Ass., 169, 1447.

Watson, C. J. and Hoffbauer, F. W. (1946). Problem of prolonged hepatitis with particular reference to the cholangiolitic type and to the development of cholangiolitic cirrhosis of the liver. Ann. intern. Med., 25, 195. 